\title{
Prevalence of caries in Brazilian children with cleft lip and/or palate, aged 6 to 36 months
}

\section{Agda Maria de Moura \\ Marcia André \\ Margareth Torrecillas Lopez \\ Reinaldo Brito e Dias}

Department of Maxillofacial Surgery, Prosthesis and Traumatology, Faculdade de Odontologia, Univ de São Paulo - USP, São Paulo, SP, Brazil.
Declaration of Interests: The authors certify that they have no commercial or associative interest that represents a conflict of interest in connection with the manuscript.

\section{Corresponding Author:}

Agda Maria de Moura

E-mail: agdamoura@usp.br

Submitted: Aug 28, 2012

Accepted for publication: Jan 28, 2013

Last revision: Feb 09, 2013
Abstract: The aim of this study was to assess the prevalence of caries in children with cleft lip and/or palate aged 6-36 months of life. This study was conducted at the University of São Paulo School of Dentistry, Brazil. A total of 143 children were selected ( 73 male, 70 female), all of whom had at least two erupted teeth. The children were distributed as follows: 88 had cleft lip and palate, 35 had cleft palate, 20 had cleft lip. Dental caries disease was diagnosed according to criteria set by the World Health Organization. It was observed that $18.9 \%$ of the study children had caries. No correlation between prevalence of caries and gender or type of cleft was observed. Mean dmf-t was 0.47 . The prevalence of caries was higher in the upper arch, and the most affected tooth was the central incisor $(p=0.001)$. Children with cleft lip and/or palate did not have high caries indices.

Descriptors: Dental Caries; Prevalence; Cleft Lip; Cleft Palate; Infant.

\section{Introduction}

Cleft lip and/or palate are among the most prevalent congenital malformations in humans, and are influenced by complex genetic and environmental factors, with relative recurrence. ${ }^{1}$ The international literature reports epidemiological indices of cleft lip and/or palate ranging from 0.87 to 1.03 per 1000 births. $^{2}$ These indices are similar to those reported in studies carried out in Brazil. ${ }^{3}$

Although not a major cause of mortality in developed countries, cleft lip and/or palate (CL/P) does cause considerable morbidity among affected children and imposes a substantial financial risk for families with a concomitant societal burden. ${ }^{4}$

$\mathrm{CL} / \mathrm{P}$ is correlated with esthetic, functional and psychological problems, and calls for early preventive interventions involving a multidisciplinary team. ${ }^{5}$

The parents of cleft patients have higher expectations regarding the effectiveness of surgical treatment. They fail to realize the close connection between oral health or speech rehabilitation and correction of the malocclusion. Therefore, it is difficult to make them understand that early caries and dental loss can affect the success of surgical treatment, orthodontic treatment and speech therapy. ${ }^{5}$

Studies have reported that children with cleft lip and/or palate are at a high risk of dental caries. Zhu et al. ${ }^{6}$, Al-Wahadni et al. ${ }^{7}$, and Stec-Slonic 
et al. ${ }^{8}$ observed that patients with a cleft condition, not only are at a high risk of caries, but also have an even higher prevalence of caries than individuals without cleft.

The classic study of Lauterstein and Mendelsohn, ${ }^{9}$ as well as the studies conducted by Lucas et al. ${ }^{10}$, King et al. ${ }^{11}$ and Tannure et al. ${ }^{12}$, found no significant differences in caries between children with and without cleft.

Regarding the type of cleft, Ankola et al. $.^{13} \mathrm{ob}-$ served that children with cleft lip were more susceptible to tooth decay than those with cleft palate. When comparing the cleft lip only or cleft palate only with the cleft lip and palate, the authors noticed that the latter showed a higher prevalence of caries. Zhu et al. ${ }^{6}$ found a higher prevalence of caries in cleft lip with or without palate. Byan et al. ${ }^{5}$ observed a higher percentage of caries in bilateral, as compared to unilateral, cleft lip and palate, and a higher prevalence of rampant caries in cleft palate.

The prevalence of caries seems to be distributed evenly between the genders of children with cleft. This finding was observed in other studies (Byan et al..$^{5}$; Neves et al. ${ }^{14}$ ).

There is relatively little information on the experience of dental caries in preschool children with cleft, and the literature ${ }^{15}$ indicates that children usually show a lower index of caries at a younger age rather than at an older age.

The purpose of the present study was to assess the prevalence of dental caries in children 6 to 36 months old, with cleft lip and/or palate, and to correlate the prevalence of caries with the cleft type, gender and age of the patients.

\section{Methodology}

This study was carried out by performing a transversal study at the University of São Paulo School of Dentistry. A project was evaluated and approved by the Ethics Committee at this university prior to conducting the study. The appropriate written consent was obtained from the children's parents/guardians. The sample size was 143 children with cleft lip and/ or palate, who had been seen at the University of São Paulo School of Dentistry outpatient clinic since their first weeks of life.
Inclusion criteria:

- cleft children,

- without multiple abnormalities,

- aged 6-36 months,

- with at least two erupted teeth, and

- with access to an optimally fluoridated public water supply.

The children with cleft lip and/or palate usually go to the clinic for cleft and not caries treatment. In addition to receiving guidance in regard to personal diet, children (or the parents/guardians of very young children) are also given specific oral hygiene education to improve their hygiene as of their first days of life. A reliable control group with the same profile and the same environmental factors could not be established.

The children were divided into five age groups:

- 6-12 months,

- 13-18 months,

- 19-24 months,

- 25-30 months and

- 31-36 months.

According to the Spina Classification, ${ }^{16}$ the cleft was divided into three types:

- cleft lip (CL), including cleft lip with or without cleft alveolus;

- cleft palate (CP), including cleft soft palate with or without cleft hard palate; and,

- cleft lip and palate (CLP).

Intraoral examination was performed by the same examiner (Kappa 1.0), following a systematic pattern: the quadrants of the mouth were examined clockwise, beginning at the most posterior upper right tooth.

Dental caries disease was diagnosed visually, with the aid of a dental mirror under artificial light (reflector), after the teeth had been dried using either gauze or air jet or else a combination of both. Dental caries disease was diagnosed according to the criteria of the World Health Organization. ${ }^{17}$ Results of the examination were recorded using the decayed, missing and filled teeth and surfaces (dmft/ $d m f s$ ) indices in the primary dentition. 
Table 1 - Sample distribution according to cleft type, gender and age, expressed in absolute numbers and percentages.

\begin{tabular}{|c|c|c|c|c|c|c|c|c|c|c|c|c|c|c|}
\hline \multirow{4}{*}{$\begin{array}{l}\text { Age group } \\
\text { (months) }\end{array}$} & \multicolumn{12}{|c|}{ Cleft type } & \multirow{3}{*}{\multicolumn{2}{|c|}{ Total }} \\
\hline & \multicolumn{4}{|c|}{ Cleft lip } & \multicolumn{4}{|c|}{ Cleft lip and palate } & \multicolumn{4}{|c|}{ Cleft palate } & & \\
\hline & \multicolumn{2}{|c|}{ Females } & \multicolumn{2}{|c|}{ Males } & \multicolumn{2}{|c|}{ Females } & \multicolumn{2}{|c|}{ Males } & \multicolumn{2}{|c|}{ Females } & \multicolumn{2}{|c|}{ Males } & & \\
\hline & $n$ & $\%$ & $\mathrm{n}$ & $\%$ & $n$ & $\%$ & $n$ & $\%$ & $n$ & $\%$ & $n$ & $\%$ & $n$ & $\%$ \\
\hline 06-12 & 3 & 2.1 & 2 & 1.4 & 9 & 6.3 & 6 & 4.2 & 2 & 1.4 & 3 & 2.1 & 25 & 17.5 \\
\hline 13-18 & 1 & 0.7 & 2 & 1.4 & 8 & 5.6 & 10 & 7.0 & 5 & 3.5 & 4 & 2.8 & 30 & 21.0 \\
\hline 19-24 & 3 & 2.1 & 2 & 1.4 & 9 & 6.3 & 9 & 6.3 & 1 & 0.7 & 6 & 4.2 & 30 & 21.0 \\
\hline $25-30$ & 1 & 0.7 & 1 & 0.7 & 8 & 5.6 & 11 & 7.7 & 6 & 4.2 & 0 & 0.0 & 27 & 18.9 \\
\hline $31-36$ & 2 & 1.4 & 3 & 2.1 & 7 & 4.9 & 11 & 7.7 & 5 & 3.5 & 3 & 2.1 & 31 & 21.7 \\
\hline \multirow{2}{*}{ Total } & 10 & 7.0 & 10 & 7.0 & 41 & 28.7 & 47 & 32.9 & 19 & 13.3 & 16 & 11.2 & \multirow{2}{*}{143} & \multirow{2}{*}{100} \\
\hline & & 20 & 0\%) & & & 881 & 6\%) & & & 35 & $5 \%)$ & & & \\
\hline
\end{tabular}

Table 2 - Correlation between dental caries and cleft type, gender and age group expressed in absolute numbers and percentages.

\begin{tabular}{|c|c|c|c|c|c|c|c|c|c|c|c|c|c|c|c|c|c|c|c|c|c|c|}
\hline \multirow{3}{*}{ Caries } & \multicolumn{6}{|c|}{ Type of cleft } & \multicolumn{4}{|c|}{ Gender } & \multicolumn{10}{|c|}{ Age group (months) } & \multirow{2}{*}{\multicolumn{2}{|c|}{ Total }} \\
\hline & \multicolumn{2}{|c|}{ Lip } & \multicolumn{2}{|c|}{$\begin{array}{l}\text { Lip and } \\
\text { palate }\end{array}$} & \multicolumn{2}{|c|}{ Palate } & \multicolumn{2}{|c|}{ Females } & \multicolumn{2}{|c|}{ Males } & \multicolumn{2}{|c|}{ 06-12 } & \multicolumn{2}{|c|}{ 13-18 } & \multicolumn{2}{|c|}{$19-24$} & \multicolumn{2}{|c|}{$25-30$} & \multicolumn{2}{|c|}{$31-36$} & & \\
\hline & $\mathrm{n}$ & $\%$ & $\mathrm{n}$ & $\%$ & $\mathrm{n}$ & $\%$ & $\mathrm{n}$ & $\%$ & $\mathrm{n}$ & $\%$ & $\mathrm{n}$ & $\%$ & $n$ & $\%$ & $n$ & $\%$ & $n$ & $\%$ & $\mathrm{n}$ & $\%$ & $\mathrm{n}$ & $\%$ \\
\hline Yes & 3 & 2.1 & 18 & 12.6 & 6 & 4.2 & 13 & 9.1 & 14 & 9.8 & 0 & 0 & 1 & 0.7 & 4 & 2.8 & 10 & 7.0 & 12 & 8.4 & 27 & 18.9 \\
\hline No & 17 & 11.9 & 70 & 49.0 & 29 & 20.3 & 57 & 39.9 & 59 & 41.3 & 25 & 17.5 & 29 & 20.3 & 26 & 18.2 & 17 & 11.9 & 19 & 13.3 & 116 & 81.1 \\
\hline \multirow{2}{*}{ Total } & 20 & 14.0 & 88 & 61.5 & 35 & 24.5 & 70 & 49.0 & 73 & 51.0 & 25 & 17.5 & 30 & 21.0 & 30 & 21.0 & 27 & 18.9 & 31 & 21.7 & \multirow{2}{*}{143} & \multirow{2}{*}{100} \\
\hline & & & $p=$ & 0.613 & & & & $p=c$ & .729 & & & & & & $p<$ & 0.001 & & & & & & \\
\hline
\end{tabular}

The data obtained were analyzed statistically using the chi-squared test, adjusted by Fisher's statistical method, in order to establish the relationship among caries prevalence and gender, age and cleft type. The difference was considered statistically significant when the $p$ value was less than 0.05 .

\section{Results}

Table 1 shows the distribution of the study population, comprised of 143 cleft patients. The patients were classified according to gender, age and cleft type.

The study observed that $18.9 \%$ of the children had caries. The prevalence of caries was similar in both males and females (Table 1 ) and did not correlate with the type of cleft ( $p=0.613$ ) (Table 2).

The number of children with caries increased with age, and significant correlation was observed between these two variables $(p<0.001)$ (Table 2$)$.

The mean $d m f-t$ was 0.47 , with very low severity according to FDI $^{18}$ (Table 3). Of the teeth examined, 62 were decayed and 5 were filled; no teeth had been extracted. Caries disease was found to be more prevalent in the upper as opposed to the lower arch. In the upper arch, caries disease was significantly more prevalent in the central incisors $(p=0.044)$, whereas, in the lower arch, caries disease was more prevalent in the first molars $(p<0.001)$.

\section{Discussion}

The low index of caries found in this study is a significant result in terms of the dental health of children with cleft. This evidence demonstrates that when children with cleft lip and/or palate participate in prevention programs and receive fluoride supplementation, they can achieve lower indices of 
Table 3 - Severity level of caries.

\begin{tabular}{|c|c|c|c|c|c|c|c|c|}
\hline \multirow{2}{*}{$\begin{array}{c}\text { Age } \\
\text { group } \\
\text { (months) }\end{array}$} & \multirow{2}{*}{$\Sigma$ Children } & \multirow{2}{*}{$\begin{array}{l}\Sigma \text { Children } \\
\text { with } d / m / f\end{array}$} & \multicolumn{2}{|c|}{$\Sigma d+m+f$} & \multirow{2}{*}{$d m f-t$} & \multirow{2}{*}{ Severity* } & \multirow{2}{*}{ dmf-s } & \multirow{2}{*}{ Severity } \\
\hline & & & Teeth & Surfaces & & & & \\
\hline 06-12 & 25 & 0 & 0 & 0 & 0 & very low & 0 & very low \\
\hline $13-18$ & 30 & 1 & 3 & 3 & 0.10 & very low & 0.10 & very low \\
\hline $19-24$ & 30 & 4 & 7 & 7 & 0.23 & very low & 0.23 & very low \\
\hline $25-30$ & 27 & 10 & 21 & 32 & 0.77 & very low & 1.18 & low \\
\hline $31-36$ & 31 & 12 & 36 & 65 & 1.16 & low & 2.09 & moderate \\
\hline Total & 143 & 27 & 67 & 107 & 0.47 & very low & 0.74 & very low \\
\hline
\end{tabular}

*FDI.

caries than the general population, despite the high risk of caries promoted by a cleft disorder.

Cleft children require adjustments to be made in diet and breastfeeding. Parents/guardians are counseled to give cleft children milk, juice and foods in general more frequently. This may lead to the accumulation of food debris. However, this frequency is essential to provide the nourishment and weight gain that are central to the development of the child. ${ }^{5}$ After reconstructive surgery, the remaining tissue, scar retraction and persistent fistulas, as well as dental anomalies of number, position, shape and structure, are risk factors for caries. ${ }^{19}$ They may pose an obstacle to ensuring effective oral hygiene, ${ }^{19,20}$ usually overlooked because of parental anxiety.

Dental caries disease is currently defined as a biosocial disease, the prevention of which is not limited to specific measures. The parents of cleft lip and/or palate children seen at the clinic of the Department of Maxillofacial Surgery, Prosthesis and Traumatology of the University of São Paulo School of Dentistry as of the first weeks of life are instructed on the importance of oral health and how to maintain it. Special focus is given to the risk factors for caries in children with cleft lip and/or palate. In addition, the parents are instructed on how to avoid other risk factors, such as inadequate diet and poor oral hygiene.

Wong and King ${ }^{15}$ reported that there are few studies investigating oral care in cleft children, and also found various inconsistencies in these studies. They concluded that the prevalence of caries may be higher in cleft individuals than in the general population. The authors suggested that the care given to these children should follow a protocol in which priority is given to oral care prior to surgical procedures.

Based on the caries risk proposed by Fejerskov, ${ }^{21}$ it could be inferred that children with cleft lip and/ or palate are at a high risk for caries. However, only $18.9 \%$ of the children investigated in the present study had caries (Table 2), which was a surprisingly positive finding.

Clinically, it was observed that the cleft children of this research, seen at the clinic of the Department of Maxillofacial Surgery, Prosthesis and Traumatology of the University of São Paulo School of Dentistry, had a low prevalence of caries, and lower indices than those found in the general population. In the present study, the mean $d m f-t$ was 0.47 . Our findings are not in accordance with another study carried out in Brazil, ${ }^{14}$ which reported higher mean $d m f-t$ indices. According to Bönecker et al..$^{22}$, the mean caries indices for the general population have decreased in the last decade. Therefore, the findings of the present report may be explained by this general reduction in the caries indices.

A study investigating the initial acquisition of S. mutans reported that it occurs at approximately 26 months of age, ${ }^{23}$ whereas another study reported that initial $S$. mutans colonization may occur as early as 14 months of age if there is greater sucrose consumption. ${ }^{24}$ Bokhout et al. ${ }^{25}$ reported a case of S. mutans colonization in an 18-month-old child. In the present study, a 16-month-old child show- 
ing early $S$. mutans colonization had three decayed teeth. However, even if cleft children are colonized at the same age as noncleft children, they may have a lower prevalence of caries because tooth eruption in cleft individuals is delayed, especially at the affected site. ${ }^{19,26}$ It is likely that teeth with delayed eruption are less exposed to risk factors, and that cleft children have a lower chance of developing caries at this age. It is noteworthy to mention that several one-year-old children were not included in our study because they did not have any erupted teeth.

Some authors have reported that $S$. mutans is vertically transmitted from mother to child..$^{25,27}$ Therefore, it has been suggested that prevention programs should include the education of family members, focusing especially on the habits of the mother. ${ }^{28}$

The analysis of the results for caries development showed that the prevalence of caries increased with age. The literature is unanimous in reporting the correlation between the prevalence of caries and age in both cleft ${ }^{5,8,13}$ and noncleft children. ${ }^{22}$ Our study population was divided into five age groups, namely 06-12 months, 13-18 months, 19-24 months, 25-30 months and 31-36 months.

The number and percentage of children in each of the aforementioned groups who developed caries were $0(0.0 \%), 1(0.7 \%), 4(2.8 \%), 10(7.0 \%)$ and $12(8.4 \%)$, respectively.

Caries was observed in 27 children (Table 2).

In the present study, the prevalence of caries was similar between males and females (Table 2), which is in accordance with the findings of other studies. ${ }^{5,14}$ Studies carried out in Brazil involving noncleft individuals have also reported similar prevalence of caries among males and females. ${ }^{22}$

Assessing the prevalence of caries according to cleft type, a greater number of children with cleft lip and palate developed caries. This could be due to a higher prevalence of this type of cleft. However, statistical analysis showed no significant correlation between caries prevalence and cleft type (Table 2), which corroborates the results of other studies. ${ }^{13}$
With regard to the distribution of caries, a higher prevalence was observed in the upper central incisors, followed by the upper lateral incisors and the lower first molars. This is in accordance with the findings of Neves et al. ${ }^{14}$, who reported a higher prevalence of caries in the left upper central incisors. It is known that left unilateral cleft is the most prevalent type of cleft, and that the teeth adjacent to the cleft are the most susceptible to caries, since they are more affected by dental anomalies of position and shape. Studies investigating children in the general population have also reported a higher prevalence of caries in the upper central incisors and lower first molars. ${ }^{22}$

The low caries indices found in the present study could be attributed to the fact that the children we assessed have been undergoing treatment (for the cleft, not for caries) at the clinic of the Department of Maxillofacial Surgery, Prosthesis and Traumatology of the University of São Paulo School of Dentistry, as of their first weeks of life.

The optimal level of fluoride in the water of São Paulo $(0.7 \mathrm{mg} / \mathrm{L})$, as well as parental education regarding breastfeeding, diet, oral hygiene and parafunctional habits, may have contributed to the low indices of caries that we found. Parental education on cleft-related issues has been given at the clinic of the Department of Maxillofacial Surgery, Prosthesis and Traumatology of the University of São Paulo School of Dentistry in recent years. Monthly appointments are scheduled until the child is two years old. The results of this educational effort, involving the families of children with cleft lip and/or palate, provide further evidence that prevention is central to the oral health and appropriate development of cleft children.

\section{Conclusion}

We concluded that children with cleft lip and/or palate did not have high caries indices, regardless of gender or cleft type. In addition, the prevalence of caries was directly proportional to age and correlated with the upper arch, particularly the upper central incisor, found to be the most affected by caries. 


\section{References}

1. Dixon MJ, Marazita ML, Beaty TH, Murray JC. Cleft lip and palate: understanding genetic and environmental influences. Nat Rev Genet. 2011 Mar;12(3):167-78.

2. Derijcke A, Eerans A, Carels C. The incidence of oral clefts: a review. Br J Oral Maxillofac Surg. 1996 Dec;34(6):488-94.

3. França CMC, Locks A. Incidência das fissuras lábio-palatinas de crianças nascidas na cidade de Joinville (SC) no período de 1994 a 2000. J Bras Ortodon Ortop Facial. 2003 SepOct;8(47):429-36.

4. Wehby G, Cassell CH. The impact of orofacial clefts on quality of life and healthcare use and costs. Oral Dis. 2010 Jan;16(1):3-10.

5. Byan Z, Du M, Bedi R, Holt R, Jin H, Fan M. Caries prevalence and oral health behavior in Chinese children with cleft lip and/or palate. Pediatr Dent. 2001 Sep-Oct;23(5):431-4.

6. Zhu WC, Xiao J, Liu Y, Wu J, Li JY. Caries experience in individuals with cleft lip and/or palate in China. Cleft Palate Craniofac J. 2010 Jan;47(1):43-7.

7. Al-Wahadni A, Alhaia EA, Al-Omari MA. Oral disease status of a sample of Jordanain people ages 10 to 28 with cleft lip and/or palate. Cleft Palate Craniofac J. 2005 May;42(2):304-8.

8. Stec-Slonic M, Szczepanska J, Hirschfelder U. Comparison of caries prevalence in two populations of cleft patients. Cleft Palate Craniofac J. 2007 Sep;44(5):532-7.

9. Lauterstein AM, Mendelsohn M. An analysis of the caries experience of 285 cleft palate children. Cleft Palate J. 1964 Jul;1(29):314-9.

10. Lucas VS, Gupta R, Ololade O, Gelbier M, Roberts GJ. Dental health indices and caries associated microflora in children with unilateral cleft lip and palate. Cleft Palate Craniofac J. 2000 Sep;37(5):447-52.

11. King NM, Wong WL, Wong HM. Caries experience of chinese children with cleft lip and palate. 2012 Mar 1. Epub ahead of print.

12. Tannure PN, Costa MDE, Küchler EC, Romanos IC, Granjeiro JM, Vieira AR. Caries experience in individual with cleft lip and palate. Pediatr Dent. 2012 Mar-Apr;34(2):127-31.

13. Ankola AV, Nagesh L, Hegde P, Karibasappa GN. Primary dentition status and treatment needs of children with cleft lip and/ or palate. J Indian Soc Pedod Prev Dent. 2005 Jun;23(2):80-2.

14. Neves LT, Gomide MR, Costa B, Ciamponi AL. Comportamento da doença cárie de portadores de fissuras lábio palatinas entre 7 e 66 meses. Pesqui Odontol Bras. 2002 AgoSep;16(supl):185-7.

15. Wong FWL, King NM. The oral health of children with clefts - a review. Cleft Palate Craniofac J. 1998 May;35(3):248-54.
16. Spina V, Psillakis JM, Lapa FS, Ferreira MC. Classificação das fissuras lábio-palatinas. Sugestão de modificação. Rev Hosp Clin Fac Med São Paulo. 1972;27(1):5-6.

17. World Health Organization. Oral health surveys. Basic methods. 4th ed. Geneva: World Health Organization; 1997.

18. Global goals for oral health by the year 2000. Fédération Dentaire Internationale. Int Dent J. 1982 Mar;32(74):74-7.

19. Cheng LL, Moor SL, Ho CTC. Predisposing factors to dental caries in children with cleft lip and palate: a review and strategies for early prevention. Cleft Palate Craniofac J. 2007 Jan;44(1):67-78.

20. Lai MC, King NM, Wong HM. Abnormalities of maxillary anterior teeth in Chinese children with cleft lip and palate. Cleft Palate Craniofac J. 2009 Jan;46(1):58-64.

21. Fejerskov $\mathrm{O}$. Changing paradigms in concepts on dental caries: consequences for oral health care. Caries Res. 2004 MayJun;38(3):182-91.

22. Bönecker M, Ardenghi TM, Oliveira LB, Sheiham A, Marcenes W. Trends dental caries in 1- to 4-yeard-old children in a Brazilian city between 1997 and 2008. Int J Paediatr Dent. 2010 Mar;20(2):125-31.

23. Caufield PW, Cutter GR, Dasanayake AP. Initial acquisition of mutans streptococci by infants: evidence for a discrete window of infectivity. J Dent Res. 1993 Jan;72(1):37-45.

24. Mohan A, Morse DE, O'Sullivan DN, Tinanoff N. The relationship between bottle usage/content, age, and number of teeth with mutans streptococci colonization in 6-24-monthold children. Community Dent Oral Epidemiol. 1998 Feb;26(1):12-20.

25. Bokhout B, Van Loveren C, Hofman FX, Buijs F, Van Limbeek J. Prevalence of streptococcus mutans and lactobacilli in 18-month-old children with cleft lip and/or palate. Cleft Palate Craniofac J. 1996 Sep;33(5):424-8.

26. Duque C, Dalben GS, Aranha AMF, Carrara CFC, Gomide M, Costa B. Chronology of deciduous teeth eruption in children with cleft lip and palate. Cleft Palate Craniofac J. 2004 May;41(3):285-9.

27. Bönecker MJS, Ardenghi TM, Trindade CP, Cury P. Transmissão vertical de streptococcus mutans e suas implicações. JBP Rev Ibero Am Odontopediatr Odontol Bebê. 2004 MayJun;7(37):297-303.

28. Lin YTJ, Tsai CL. Caries prevalence and bottle-feeding practices in 2-years-old children with cleft lip, cleft palate, or both in Taiwan. Cleft Palate Craniofac J. 1999 Nov;36(6):522-6. 